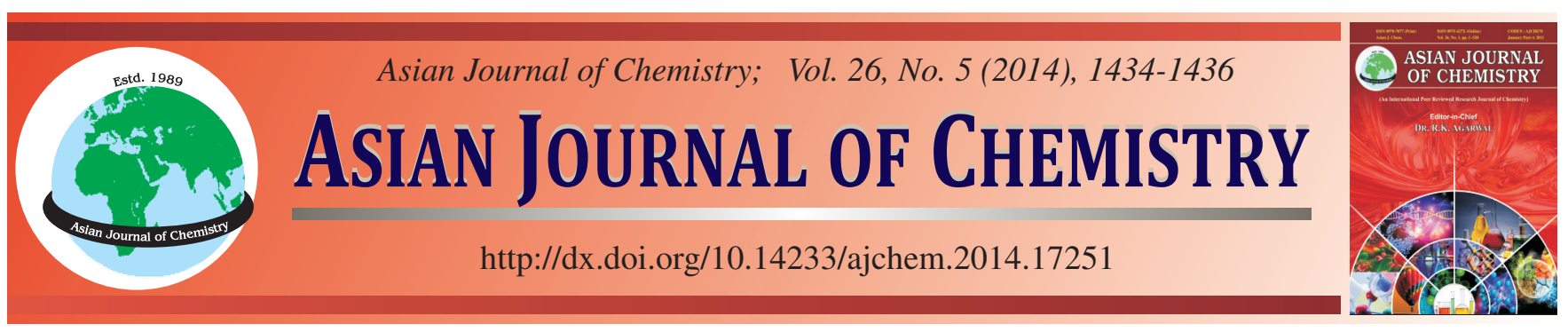

\title{
Effect of Heat Treatment on Properties of LGJW20 Steel $\dagger$
}

Ping Li ${ }^{1,2, *}$, Ning LiU ${ }^{1}$, Shaofeng Zhu ${ }^{2}$ and Xinje Chen ${ }^{1}$

${ }^{1}$ School of Materials Science and Engineering, Hefei University of Technology, Hefei 230009, P.R. China

${ }^{2}$ Anhui Jianzhu University, Hefei 230022, P.R. China

*Corresponding author: Tel: +86 13855120105; E-mail: ccliping2005@126.com

Published online: 1 March 2014;

AJC-14792

This paper prepared steel composites LGJW20 containing $20 \%$ tungsten carbide particles by centrifugal casting method and its substrate material was GCr15 bearing steel. In this study, the material was treated by heat treatment. The metallographic analysis, XRD and SEM, and the performance of the alloy was represented with Vickers hardness and bending strength. Organizational defects were effectively eliminated in annealing process. When the material was quenched at $980{ }^{\circ} \mathrm{C}$, martensitic structure is maximized and Vickers hardness reaches the maximum, during which the quenching effect is the best.

Keywords: Heat treatment, Microstructure, Hardness, Bending strength.

\section{INTRODUCTION}

Particle reinforced composites possess a variety of excellent performance that whisker and short fiber reinforced metal matrix composites has. But considering its low plastic and toughness, its application is limited in demanding environment $^{1}$.

After a long period of study, Xian-Qing You and his group from Hefei University of Technology successfully put centrifugal casting process in making particle reinforced steel matrix composites. The composite material has high density and stability, but some defects, such as uneven distribution of particles and segregation phenomenon of alloying elements. On this basis, this paper studies the effect of heat treatment on centrifugal casting samples in order to eliminate the tissue defect, which can improve the mechanical properties of particle reinforced steel matrix composites ${ }^{2}$.

\section{EXPERIMENTAL}

See bearing steel GCr15 as matrix, steel matrix composites containing $20 \% \mathrm{WC}$ particles are made by centrifugal casting process. Sample $6 \mathrm{~mm} \times 6 \mathrm{~mm} \times 35 \mathrm{~mm}$ is incised.

First stage i.e., sample handling: Original sample: preliminary grinding, grinding and fine grinding, polishing. Then carry out mechanics performance testing with universal tester and Vickers hardness tester. At last, microstructure analysis is made by XRD and SEM and microscopic analysis after $9 \%$ nitric acid alcohol dealing with the sample surface.

Second stage i.e., annealing treatment: GCr15 belongs to high carbon steel. The spheroidizing annealing treatment is adopted by common steel spheroidizing isothermal annealing process $^{3}$.

Considering actual material, the addition of WC makes element content of $\mathrm{W}$ in the steel substrate increase and eutectoid temperature is improved. So the annealing temperature curve is shown in Fig. 1.

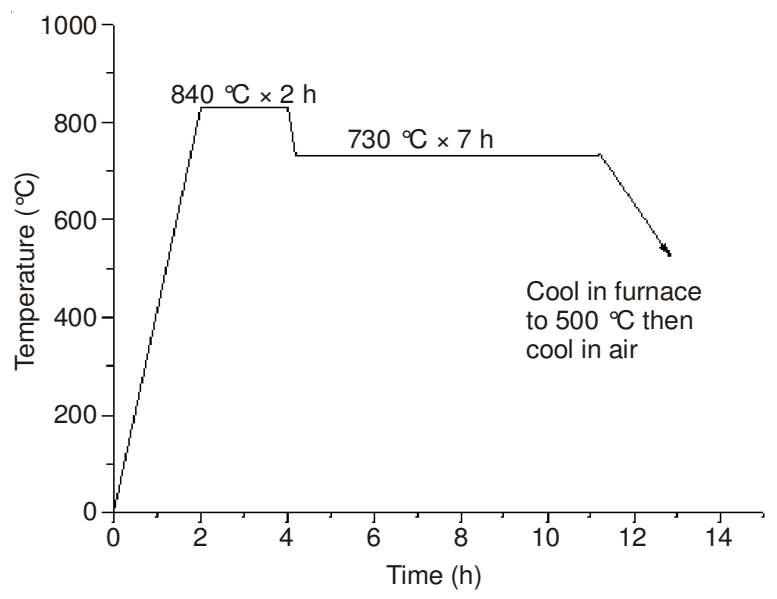

Fig 1. Annealing temperature curve 
Third stage i.e., quenching and tempering treatment: After sample is annealed, different temperature is chosen for quenching treatment. Different quenching process: 900, 950, 980 and $1000^{\circ} \mathrm{C}$ for $20 \mathrm{~min}$ and oil quenching. Quenching is happening in high temperature furnace. In order to prevent high temperature oxidation, sample is submerged in crucible during the test, in which there is nanometer alumina. Then put the sample in electric furnace for low tempering, then thermal insulation for $2 \mathrm{~h}$ at $200{ }^{\circ} \mathrm{C}$ and air cooling at last.

\section{RESULTS AND DISCUSSION}

Characterization of mechanical properties: On the basis of the tests, Vickers hardness of annealing sample decreased from original 287(HV10) to 251. From Fig. 2, different quenching temperature has different effect on the mechanical properties of steel bonded carbide. With the increase of quenching temperature, sample hardness increases and it reaches the maximum at $980{ }^{\circ} \mathrm{C}$. After that hardness decreases with the increase of quenching temperature.

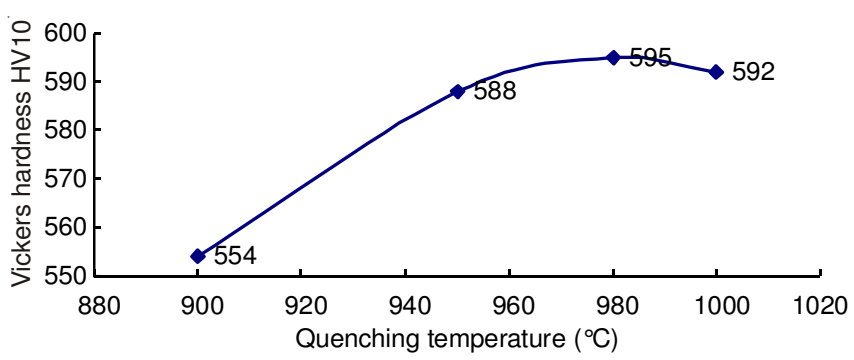

Fig. 2. Influence of quenching temperature on hardness

Martensite is the main factors that influence the hardness of the steel matrix. Martensite in the sample increases as the quenching temperature rises and hardness rises. At $980{ }^{\circ} \mathrm{C}$, martensite transformation reaches the maximum value, material hardness and abrasive resistance are significantly enhanced. Tempering treatment eliminates the stress produced during the quenching, which improves hardness and abrasive resistance of steel and plasticity and toughness as well. After quenching temperature rises, a large amount of residual austenite are created in samples, which increase the strength and hardness value of the alloy ${ }^{4}$.

Fig. 3 suggested that after quenching treatment and tempering treatment, bending strength of original sample decreases first and then rises. The value reaches the minimum at $980{ }^{\circ} \mathrm{C}$, then increases when temperature rises.

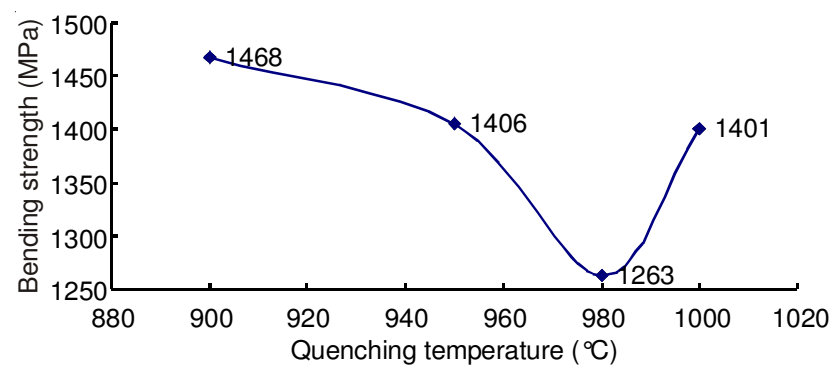

Fig. 3. Influence of quenching temperature on bending strength

Because austenite in steel substrate is transformed to martensite during quenching process, hardness rises and toughness decreases, which results in bending strength decreases. Martensite transformation reaches the maximum at $980{ }^{\circ} \mathrm{C}$, while hardness value is the highest and toughness is the lowest, which leads to bending strength reach the minimum. When quenching temperature is too high, large amounts of carbide are dissolved in austenite, which make carbon and alloy elements content in the austenite increase and the Ms and Mf point of steel is reduced, meanwhile both toughness and bending strength increase.

Organization structure analysis: Compared with original sample, for sample after quenching treatment at $980{ }^{\circ} \mathrm{C}, \mathrm{FeC}$ and $\mathrm{Fe}_{7} \mathrm{C}_{3}$ are remained while $\mathrm{CrC}_{3}$ is newly increased.

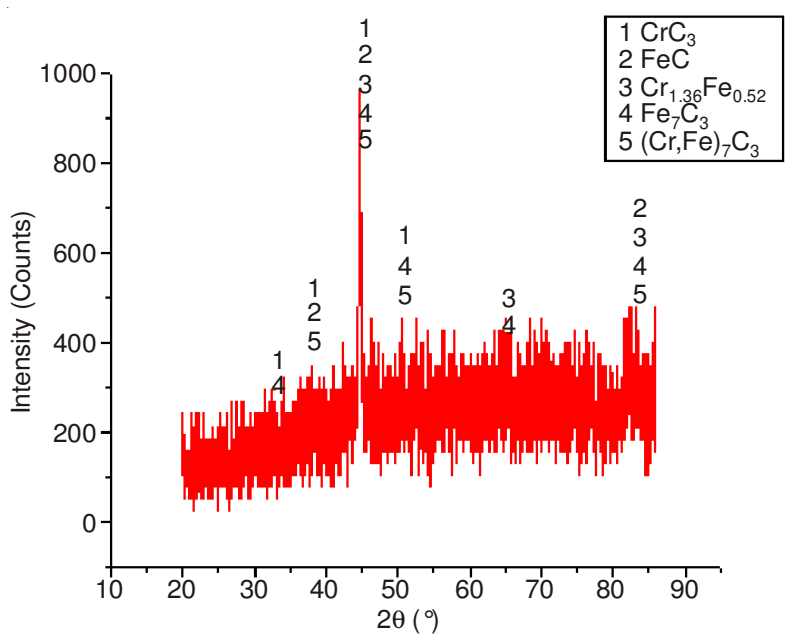

Fig. 4. XRD of quenching and tempering sample at $980{ }^{\circ} \mathrm{C}$

Fig. 5a showed that the main ingredients are black pearlite, network carbide, massive carbides and few tungsten carbide particles aggregate. A lot of tissue defects, uneven distribution of elements and harmful carbide exist in original structure, which greatly reduce the mechanical properties of LGJW20 $0^{1,5}$.

The distribution of structure organization is more uniform after sample is quenched and tempered, fishbone and dendritic carbide increase (Fig. 5). Uniformity is the highest at $980{ }^{\circ} \mathrm{C}$, while pearlite transformation and sample hardness reach the maximum, but toughness is low. At $1000{ }^{\circ} \mathrm{C}$, herringbone and net structure begin to be destroy, which causes mechanical property of sample decrease.

From Fig. 6, when sample is quenched at $980{ }^{\circ} \mathrm{C}$ and tempered at $200^{\circ} \mathrm{C}$, a large number of acicular martensitic structure are created in matrix. This martensite has different shapes, such as massive, nets, dendritic, etc.

In the process of centrifugal casting, tungsten carbide has small particle diameter dissolved or collapsed at high temperature and those has not been dissolved grow up as heterogeneous nucleation of the basement, then form tiny carbides(as shown a, c in figure A). After sample is quenched, undissolved carbide during annealing starts to dissolving and mixing into steel matrix and tungsten carbide particles start to dissolving as well. However, tungsten carbide particles need high temperature to dissolve, part of the particles form small white particles (Fig. B), which attached on the surface of the matrix. It increases the obdurability of steel composite material at a certain extent ${ }^{6}$. 


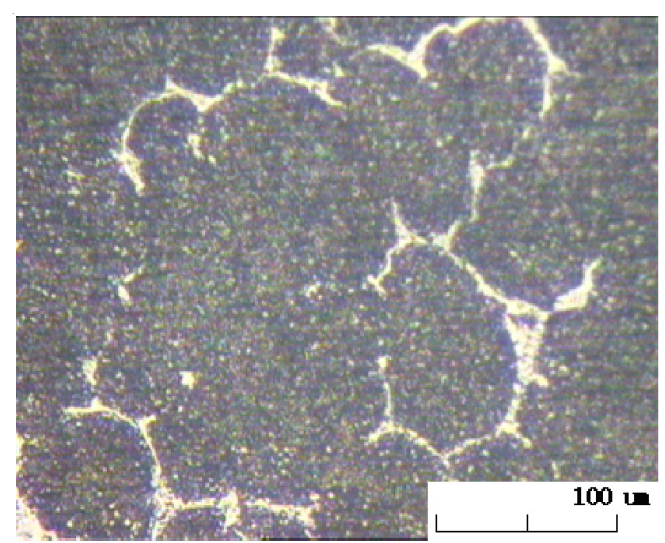

a. annealing sample

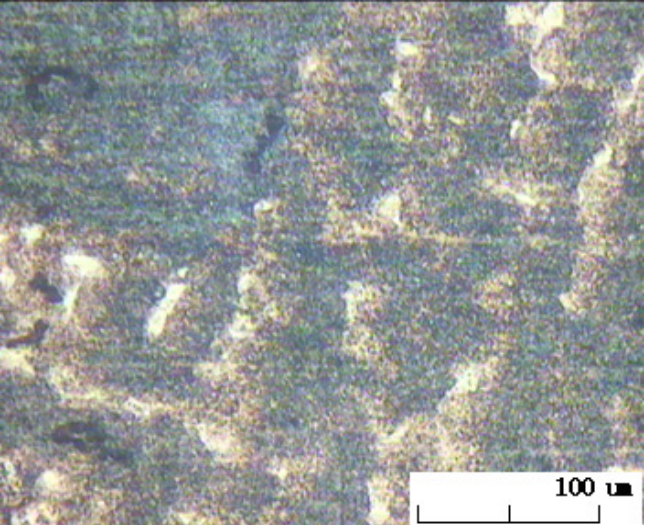

c. $980^{\circ} \mathrm{C}$ quenching

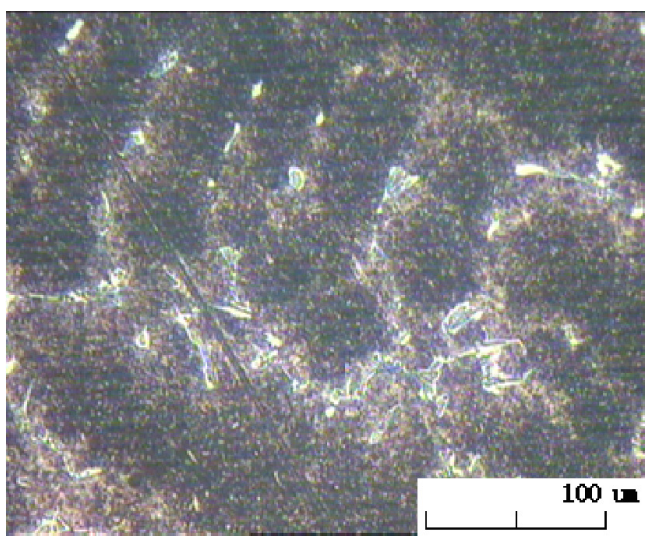

b. $950 \stackrel{\circ}{\mathrm{C}}$ quenching

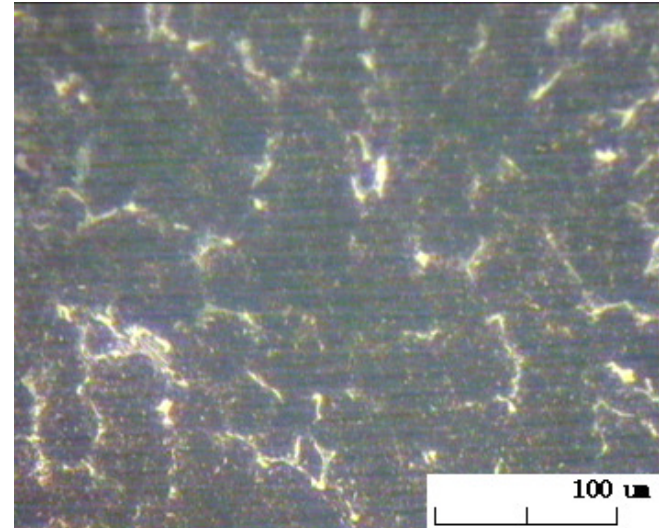

d. $1000 \stackrel{\circ}{C}$ quenching

Fig. 5. Microscopic structure of sample
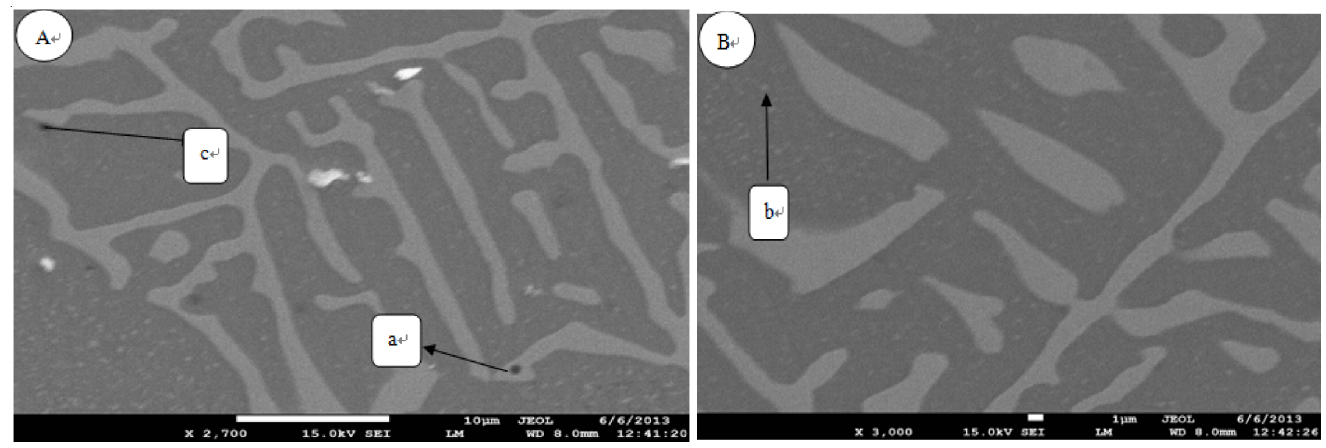

Fig. 6. $980{ }^{\circ} \mathrm{C}$ quenching SEM morphology

\section{Conclusion}

After sample is annealed, its hardness decreases while bending strength increases. Quenching and tempering treatment enhance hardness of the sample, while reduce its bending strength. Martensite transformation reaches the maximum when quenching at $980^{\circ} \mathrm{C}$. When the temperature is over 980 ${ }^{\circ} \mathrm{C}$, carbide in the organization begins to dissolve, net broken, fragmentation and such phenomena, which improve the whole obdurability of material at certain extent. It results in sample's hardness drops and bending performance increases. Annealing process removes tissue defects, dissolved carbide and separate out, tissue homogenization; quenching process: a large amount of carbides dissolve, fishbones and dendritic carbide increase, matrix is transformed into quenching martensite structure. High temperature leads to herringbone and herringbone broken.

\section{REFERENCES}

1. A.J. Liu, Master's Thesis, Effect of heat treatment on microstructure and properties of WC/steel bonded carbide, Hefei University of Technology (2012).

2. L. Bao, Master's Thesis, Effect of heat treatment on microstructure and properties of WC/steel composites by centrifugal casting, Hefei University of Technology, p. 3 (2009).

3. C. Hongnian and M. Jianping, Modern Heat Treatment, Chemical Industry Press, pp. 125-125 (2010).

4. S. Xuefeng, Y. Xianqing and Z. Yuchun, Cemented Carbide, 22, 10 (2005).

5. L. Bao, Y. Xianqing and Z. Yan, Cemented Carbide., 25, 143 (2008).

6. X.Q. You and X.F. Song, Trans. Nonferrous Met. Soc. China, 15, 1333 (2005). 